\title{
Rituals of outspokenness and verbal conflict
}

\author{
Dániel Z. Kádár ${ }^{1}$ Melvin De La Cruz \\ School of Music, Humanities and Media \\ University of Huddersfield \\ Queensgate, Huddersfield \\ HD1 3DH \\ United Kingdom
}

\begin{abstract}
This study examines rituals of outspokenness, by analysing cases drawn from the US hidden camera show, Primetime: What Would You Do? Studying ritualistic behaviour in cases when bystanders become side participants as they stand up for victims of abuse fills a knowledge gap in pragmatics. A further merit of studying this phenomenon is that it provides insight into the reactive aspect of ritual behaviour, which is usually described in the field as a form of action rather than reaction. Furthermore, the morally loaded acts of rituals of outspokenness reveals the potentially complex relationship between aggression and normative behaviour.
\end{abstract}

\section{Keywords}

rituals; outspokenness; morality; intervention; aggression; footing

\section{Introduction}

The present study examines 'rituals of outspokenness' within episodes of intervention in a reality television programme. Ritual is a recurrent (and thus expected) performance, which (re-)enacts the normative beliefs/values of a relational network or a broader social group. For example, singing a national anthem, conferring an honorary title, and announcing a verdict in public are all ritual acts because they reenact certain social values in dramatic ways. However, the category of ritual is not limited to such formalised acts: often we interactionally co-construct rituals that belong to narrower relational networks of people. For example, retelling an 'old joke' can operate as an in-group ritual that re-enacts interpersonal values (friendship) within a relational network as a performance. In a similar way, ostracising a person through the recurrent performance of ignoring them - e.g. by not responding to their questions and ignoring their other contact attempts - can become an abusive interactionally coconstructed form of ritual behaviour, a performance that animates a group's belief that the ostracised person is unwanted (see Kádár 2013 on the interactional coconstruction of rituals).

In the context of intervention, the notion 'ritual of outspokenness' refers to the recurrent and expected dramatic action of stepping up against the committer - or group of committers - of a seemingly immoral action. ${ }^{2}$ In terms of 'footing' (see

1. Corresponding author's e-mail address: d.z.kadar@hud.ac.uk . Dániel Kádár would like to say a big thank you to the following colleagues: Francesca Bargiela-Chiappini, Jonathan Culpeper, and Rosina Marquez-Reiter. He would also like to extend his gratitude to Jacob Mey for drawing his attention to the 'Kitty Genovese' case. The authors feel indebted to the anonymous referees for their constructive and most insightful comments. It is perhaps needless to say that all remaining errors belong to us.

2. It is pertinent to note at this point that rituals of outspokenness also exist in noninterventional contexts, e.g. when a person is being ostracized (see below and also Kádár 2013). 
Goffman 1979), a ritual of outspokenness transforms a 'bystander' (or a group of bystanders), who is unratified to participate, into ratified "side participant(s)" (see Kádár and Haugh 2013: 89). A ritual of outspokenness thus reinforces situated moral expectations (Boltanski and Thévenot 2000), and it counts as a dramatic action that attempts to restore the normative order of appropriate/socially acceptable behaviour. Consequently, bystanders and observers of a setting when someone is abused tend to expect (or, at least, wish) that this ritual action will take place (from a participant perspective: 'wish that someone had the courage to put the bully back in his proper place'). Public awareness of someone's failure to (at least to attempt to) be outspoken and challenge an immoral act of abuse in some way - when they had a chance to do so - occasions shame (as shown in Section 3.2). This ritual is normative also in the sense that it requires common ground - triggered by the bystanders' empathy with the victim (see Mey 2008) ${ }^{3}$ - to be set into motion: without sharing common ground with the victim there are no rights or duties for a bystander to change their footing (see example 9). A typical ritual of outspokenness in the present data (discussed in Section 2) is represented by example (1):

(1)

Retrieved from Primetime: What Would You Do? (see Section 2)

Lesbian parents verbally abused

Lesbian couple eating breakfast with their two kids at a restaurant in Texas. The server berates and humiliates the lesbian couple. Several customers overhear the server.

1. Server: You're gay and you have kids? It's bad enough that you are lesbians but that they don't have a father [pause] I think that is kind of bad. You don't feel uncomfortable - people watching you? Isn't it bad for the kids? I think it's terrible!

2. [Lesbian couple does not answer and looks embarrassed.]

3. Young male: Sorry, but you are just being rude. It's completely inappropriate when someone comes into a restaurant to have breakfast with their family that you question their life choices.

4. Server: I just think I am entitled to my own opinion.

5. Young male: You are entitled to your opinion but this is not the place to voice your opinion.

6. Server: Is it just me that's upset? [looks in different direction in the restaurant]

7. Middle aged female: That doesn't bother me at all.

8. Server: [to the lesbian couple] You don't think it's bad for the kids that they don't have a dad? I think you guys should just leave. You are disturbing everybody else!

9. Young male: You are by far the worst waitress I have ever seen in this restaurant. Ever! You are a horrible person and a horrible waitress. Like, you need to leave. You need to physically leave this restaurant!

This interaction represents a row between a server who verbally abuses ${ }^{4}$ a lesbian couple and two customers who stand up and defend the couple. The clash takes place

3. See also Heritage and Lindström (2012) on the topic of common ground and empathy. Dániel Kádár is grateful to Jacob Mey for drawing his attention to this article. 
after the customers see that the parents, who are openly humiliated by the server's verbally aggressive behaviour, do not respond to the insulting comments (line 2). The young male immediately challenges and criticises the server, and when the server argues back, he engages in a conflictual verbal interaction with her. In line 7 , he is supported by another customer, a woman who - in response to the server's query argues that the presence of the couple does not bother her. Ritual as we can observe here is not formalised but rather interactionally co-constructed; however, the young intervening male's behaviour should be seen as ritualistic as a) he (re-)animates public opinion several times in the conversation (through the general metacomment "[i]t's completely inappropriate to..." he refers to social values rather than his personal judgement), b) he takes up the role of authority figure in a social drama (e.g. "You need to physically leave this restaurant!"), and c) his behaviour is expected (another customer feels encouraged to join in).

As this example shows, as rituals of outspokenness tend to take place when someone is/seems to be unable to defend him or herself, the victim has little active role in these interactions, and it is thus not surprising that in our data there are very few utterances produced by the victim. The normativity of the ritual of outspokenness is shown in Figure 1 (see Section 2): in the data studied, a notably large number of bystanders intervened in some form when someone was victimised in public. Furthermore, as Section 3.2 illustrates, interactional contexts of public abuse trigger awareness that not performing a ritual of outspokenness is regarded as improper.

\subsection{Scholarly importance}

The study of rituals of outspokenness has different merits for the analyst. First, research of this understudied phenomenon fills a knowledge gap in pragmatics. Although interpersonal verbal conflict has an extensive literature (see e.g. Hayashi 1996; Holmes and Marra 2004; Graham 2007; Culpeper 2011), and so does the pragmatics of empathy (see e.g. Takahashi and Beebe 1987; Wynn and Wynn 2006; Mey 2008; Burdelski 2013), this particular morally-loaded empathic ritual conflict had received little attention, despite the fact that studying this phenomenon enriches understandings of the dynamics of the interactional relationship between participants and bystanders. The phenomenon of outspokenness has, in fact, been studied in social psychological and linguistic inquiries into ostracism, as one of the 'strategies' (Sommer and Yoon 2013) for upholding relational, cultural or group norms. However, ostractism via outspokenness represents a case when members of a relational network reinforce in-group relationships by forcing a deviant member to obey interpersonal norms and contribute to the collective (see e.g. Marques 1990; Marques and Paez 1994; Dijker et al. 2007). Thus, such manifestations of ostracism operate with relational history, and they are situated in a series of events; consequently, as social psychologists Williams \& Sommer (1997), and Williams \& Zadro (2001) argue, these acts tend to have a punitive nature. ${ }^{5}$ Although ostracising is an important type of ritual of outspokenness, this ritual has another, less-known, out-group type, and the present paper examines rituals of outspokenness by focusing on this latter, one-off type event. These one-off ritual events are, in a sense, more ad hoc than their in-group

4. Note also that WWYD represents non-violent conflict; arguably, it is more difficult to intervene in acts of violence, e.g. when the abusing person is holding a weapon.

5. There are constructive and destructive rituals of ostracising outspokenness, the latter involving cases when bullies 'let the victim know their opinion' about her or him, that is, when ostracism does not serve the constructive goal of reintegrating a deviant group member. 
counterparts, which tend to follow the situated practices of a relational network (see Kádár 2013).

Second, rituals of outspokenness are noteworthy as they represent a complex interpersonal situation; this complexity may explain why these rituals have been relatively neglected in the field (but see Garcés-Conejos Blitvich 2009, 2010 as an important exception). The conflict triggered by rituals of outspokenness differs from how interpersonal conflict is usually understood. According to Cahn (1997: 61; cited in Culpeper 2011: 5), interpersonal conflict is "interaction between parties expressing opposing interests"; however, rituals of outspokenness do not represent a dyadic interpersonal conflict, but rather a trifold conflict between the wrongdoer and the victim, the wrongdoer and the outspoken person, and the wrongdoer and the broader community the outspoken person appeals to. Section 3.1 models this complex interpersonal relationship (see Figure 2 below). Furthermore, as rituals of outspokenness represent morally loaded actions, their research provides an interesting case study for language aggression and impoliteness. These rituals embody behaviour that tends to be perceived as aggression, and they are conflictive because:

- they "attack [...] positive identity values" (Culpeper 2011: 5) that the committer claims for themselves; and

- they usually manifest themselves as an interruption in front of a group of bystanders/side participants-to-be, and so they trigger conflict just as heckling does (see Kádár 2014).

However, the ritual of outspokenness (re-)enacts normative moral expectations, and so it is meant to reinforce the "moral order" (Whutnow 1989). As Culpeper (2011: 38) argues, understandings of genuine impoliteness arise as interactants violate the moral order, and so it can be argued that ritual acts of aggression such as outspokenness have an ambiguous relationship with genuine impoliteness, as the intervening people usually refer to their acts as 'righteous' (see Section 3.2). Thus, while these acts involve what conversation analysts define as a 'rights violation' (see e.g. Stivers et al. 2011), and the wrongdoer tends to be angered by this violation, others tend to appreciate it as this violation makes a contribution to the greater good. In other words, a ritual of outspokenness is usually interpreted as a ratified form of intervention (Drummond 1989) - which is immoral on the surface due to its violative nature but open to be reinterpreted as moral - and as such it essentially differs from heckling, for instance. As Section 3.1 shows, due to this ratified and normative characteristic this form of aggression tends to be mitigated to some extent.

Third, the study of rituals of outspokenness provides new insights into interactional research on rituals. In pragmatics, interpersonal ritual is usually approached as recurrent and formalised "action" that encompasses a broad range of speech acts (see e.g. Lüger 1983; Ide 1998; Alexander 2004); this action-based understanding echoes interactional discourse analytic research that touches on ritual (see Rampton's 2009 study on 'crossing') as well as sociological ritual research (see e.g. Bell 1992: 19). Yet, there is a gap between the ways in which 'action' is interpreted in these disciplines. In pragmatics and other interactional disciplines, due to their focus on language in action, 'ritual' is often interpreted in a narrow sense: a practice is performed as a means to generate some response as ends. ${ }^{6}$ In sociological

6. This is not to mean that pragmatic studies on ritual oversimplify this phenomenon. For example, Ide (1998) illustrates in an insightful way that a ritual apology in Japanese can have many interpretations, i.e. a certain means can have several ends. 
theory, on the other hand, 'ritual action' is understood more broadly; Goffman (1967: 185) states that " $[\mathrm{b}] \mathrm{y}$ the term action I mean activities that are consequential, problematic, and undertaken for what is felt to be their own sake”. Furthermore, sociologists often use 'ritual action' in reference to reactive forms of behaviour. For example, Collins (2004: 110) notes that certain types of ritual are reactions by their nature: "[i]n the Durkheimian model, violation of solidarity brings the reaction of righteous anger; this results in yet another highly ritualised interaction, a ritual of punishment.” The present study aims to consolidate this interdisciplinary gap, by adopting the broad interpretation of ritual action with the aim to examine the phenomenon of reactive ritual within the boundaries of language use. Rituals of outspokenness, which come into existence via the stimuli of public abuse, are examples par excellence for a reactive ritual action. We argue that there is no significant typological difference between reactive and other rituals, in that reactive rituals are normative and expected like any other ritual. In order to illustrate this point, in Section 3.2 we examine the relationship between context and ritual reaction, and show that there are certain situations that trigger a straightforward ritual response. That is, there are conventional expectances as regards the occurrence of rituals of outspokenness; we illustrate this point by examining retrospective comments of those who perform or fail to perform these rituals.

\section{Data}

As Kádár (2013) argued in a recent publication, it is difficult to find data that represents ritual abuse in interaction, and this problem also applies to the ritual of outspokenness, in particular its one-off out-group type studied in this paper. As abuse that triggers a ritual response(s) is a behavioural anomaly from a normative point of view, it is difficult for the analyst to anticipate and record such events, even though there are a number of accidental video recordings (on video sharing websites) and fictional data in films that represent such events. There is, however, a US hidden camera show, Primetime: What Would You Do? (henceforth WWYD), ${ }^{7}$ which is dedicated to this form of behaviour, and which thus serves as the main source of data for this paper. ${ }^{8}$

WWYD, hosted by the reporter John Quiñones, premiered on the ABC television network in the United States in 2008. The theme behind the show is that actors act out scenes in which some type of conflict or illegal activity occurs; there are hidden cameras that record the event, and the focus is on whether bystanders intervene, if yes, how, and if no, why. Most of the scenes take place in orderly urban settings, in which the conflictive/illegal activity is even more salient. The show has a news feature, i.e. in follow-up interviews Quiñones queries those who intervene and others who do not, and so the episodes provide information on the language users' reflections on their own behaviours. The scenes feature bystanders' attitudes towards abuse in racial, gender, ethics, sexuality, and disability contexts, as well as in a range of surprising/upsetting scenes, such as when a mother and a child cannot afford to buy a Christmas tree. In the present research we focus on the former cases, by studying 21 scenes of abuse depicted in WWYD, which include altogether 117 video recordings of 2-3 minutes in length (21,170 words of transcript, excluding annotations of non-

7. See: <http://abc.go.com/shows/what-would-you-do>

8. It is pertinent to note that WWYD is not the first of such shows - in a sense it can be regarded as 'inheritor' of the British series Candid Camera and its later versions in different countries. However, a unique feature of WWYD, as far as we are aware, is that it focuses on social problems and abuse in particular. 
verbal actions). It is necessary to note that the way in which we transcribed the data reflects our predominantly interactional interest in the dynamics of ritual as a reactive form of behaviour; thus, we focus on ritual on an utterance level in a turn-by-turn way, instead of examining the conversational analytic features of interactions (for micro-level interactional analysis of rituals see Kádár 2013). Also note that in order to facilitate reading of the examples presented, in each extract we add an arrow to the line in which the ritual of outspokenness takes place/begins to unfold.

In 105 of the 117 respondent recordings the bystander intervenes in some form, that is, the rate of intervention is $89.7 \%$ (see Section 1 ). ${ }^{9}$ We do not intend to regard this rate by itself as of evidence value: intervention rate may be different in 'real-life' situations, considering that the abusive scenes in WWYD were designed to trigger the bystanders' notice and intervention, whilst non-predesigned forms of reallife public abuse may as well go unnoticed. Without exception in our data, the predesigned abusive events take place in the proximity of a few but not too many bystanders. This arrangement seems to us to ensure that the bystanders gain a proper understanding of what is going on, and to prevent what social psychologists often describe as the 'Kitty Genovese effect' (Manning et al. 2007), in reference to a famous murder case in New York City when a woman was killed and raped, and the neighbours failed even to call the police in time, supposedly because they expected others to do something. In WWYD, as there are not many others around to intervene on the individual's behalf, there is a pressure on the individual to intervene. Furthermore, we have no means to look into the production of the interviews behind the scenes, and there is a possibility that the series simply does not feature some of the intervention and non-intervention cases. Nevertheless, this is still a notably high frequency rate, considering that the reports aim to feature the failure of nonintervention as much as intervention, and that this figure represents an overall frequency rate in the various setting types. Thus, it is safe to argue that intervention has a normative nature when it comes to public abuse, and Section 3.2 draws upon further evidence to support this claim.

An advantage of studying WWYD is that it is a specific type of reality show: a docudrama or a fly on the wall documentary made with the help of secret cameras (see more in Lorenzo-Dus and Garcés-Conejos Blitvich 2013). Because of this, the bystanders are unaware that they were being observed, which is important for the analyst, considering that not performing rituals of outspokenness occasions shame (see Section 3.2). In other words, anticipation triggered by “double articulation”, i.e. "a communicative interaction between those participating in discussion, interview, game show or whatever, and, at the same time, is designed to be heard by absent audiences" (see Scannell 1991:1, cited in Lorenzo-Dus and Garcés-Conejos Blitvich 2013:32) - does not influence the interactional behaviour of the bystanders.

In order to support the findings, along with the WWYD data we also examined 17 North American anti-bullying promotional films, such as "Anti-Bullying - Kill The Silence", ${ }^{10}$ in which bystander behaviour is featured. These films confirmed our findings about the shame value triggered by failure to intervene in settings of abuse:

9. The actual rate might be slightly different from this figure, as there are some side participants whose intervention does not qualify as a ritual of outspokenness (see example 10). However, there are also some bystanders who failed to intervene but made some passive attempts to align with the victim, e.g. looking round for help. However, as the number of participants on these sides largely coincide ( 4 to 5 ), the roughly $90 \%$ intervention rate seems to be a reliable figure.

10. See: < https://www.youtube.com/watch?v=SJxWAYEcl_s $>$ 
several of these promotional films depict passive bystanders who failed to help and who regret this failure in retrospect. We also made use of 25 interviews that the first author conducted in Hungary (Kádár 2013). Whilst most of these interviews concern recurrent in-group verbal abuse and rituals of outspokenness in such situations, they confirm what WWYD shows about the 'moral obligation' of bystanders to intervene in the event of an abuse (see Section 3.2).

\section{Analysis}

We approach the phenomenon of rituals of outspokenness by focusing on the two bystander attitudes of intervention and non-intervention in situations of public abuse, and the footings that these attitudes trigger. Section 3.1 examines cases when the bystander becomes a side participant through performing the ritual of outspokenness. We first analyse outspoken behaviour, by approaching it from the perspective of (dis)alignment (Goffman 1967), and also by looking into types of 'conversational argumentation' (Van Dijk 1997) applied in these ritual acts. On the basis of the (dis)affiliative attitudes of the interveners, we elaborate an interpersonal interactional model of rituals of outspokenness. In section 3.2 we look into the reactive and normative nature of rituals of outspokenness: we examine the 'moral obligation' (Gorsuch and Ortberg 1983) of bystanders to intervene triggered by acts of abuse, by focusing on the perceptions of those who fail to intervene, and who were queried by Quiñones regarding their failure to intervene.

In this paper we use the terms 'alignment' and 'disalignment' in the sense in which they are understood in social psychology, to describe actions that increase/decrease cohesion between participants of an interaction. We avoid using the terms 'politeness' and 'impoliteness' because, as Section 3.1 illustrates, although there is an important interface between acts of alignment/disalignment and politeness/impoliteness, not every disaffiliative ritual of outspokenness is impolite. For instance, there are highly mitigated interventions, which express disalignment from the wrongdoer and trigger conflict on the one hand - simply because any intervention has a potential to create conflict and be interpreted as a form of aggression - and which might be evaluated as 'polite' by various participants due to their mitigated nature, on the other. Another important advantage of using alignment and disalignment relates to the scene studied: since intervention happens in the context of a clash between the wrongdoer and the victim, those who intervene essentially take sides through acting - or non-acting - i.e. from an interpersonal perspective these actions, unlike acts of (im)politeness, have no potential to operate simply within the speaker-hearer dyad.

\subsection{The act of the ritual of outspokenness}

The act of being outspoken entails alignment with the victim and disalignment from the wrongdoer. This attitude manifests itself in the following behavioural patterns in the data studied: 


\begin{tabular}{|c|c|}
\hline 1) overt conflict & $\begin{array}{l}\text { a) direct disalignment from the wrongdoer(s) and indirect } \\
\text { alignment with the victim(s) } \\
\text { b) direct disalignment from the wrongdoer(s) and direct } \\
\text { alignment with the victim(s) } \\
\text { c) mock alignment with the wrongdoer(s) and (in)direct } \\
\text { alignment with the victim(s) }\end{array}$ \\
\hline 2) covert conflict & $\begin{array}{l}\text { alignment with the victim and indirect disalignment from the } \\
\text { wrongdoer }\end{array}$ \\
\hline
\end{tabular}

Figure 1: Types of ritual outspoken behaviour

Note that there may be no clear border between the categories of overt and covert conflict, as covert conflict has a potential to transform into overt conflict and vice versa, as an interaction unfolds, and so overt and covert should be understood as two ends of a scale. The behavioural patterns above have been identified in the data studied as we realised that intervention is not a homogenous phenomenon, and consequently one should avoid using it as an umbrella term. ${ }^{11}$

In what follows, let us illustrate how these behavioural types operate. The act of a ritual of outspokenness can take place in the form of overt conflict, i.e. when the outspoken person directly challenges the wrongdoer. Example (1) represents such an overt conflict, as the outspoken customer overtly challenges the server, by uttering "Sorry, but you are just being rude". Such overt conflict can take place either via direct disalignment, as in (1), or in a more indirect form which we define as 'mock alignment'. Mock alignment covers cases when the outspoken person pretends alignment with the wrongdoer in a form that makes it clear that the given act is in fact disalignment from the wrongdoer, ${ }^{12}$ and it is illustrated by the following example:

\section{Dog left inside a hot car}

A dog has been left in the back seat of car on a very hot day and barks loudly as people pass by. It is illegal to leave a pet in a car in New Jersey.

$\square$ 1. Female: It's just so hot in there. [...] But, the police are coming right now.

2. Dog owner: You called the cops? How is any of that your concern?

3. Female: The dog is in there panting and could die. That's our concern. Not you.

In line 1 a female bystander, who seems to be willing to challenge the dog owner, addresses the wrongdoer by 'describing' the actual situation; note that she does not say anything directly about the dog's owner, but in fact she simply starts with the matter of fact statement about the condition in the car, in a non-aggressive tone of voice. This comment could even be interpreted as a friendly proposal to resolve the dog's situation, and in fact this is what a previous bystander in the same report of WWYD is doing: she attempts to rescue the dog simply by drawing the owner's

11. Tendency-wise a difference can be observed between these patterns: amongst the 117 interactions studied, in 98 the intervening person applies a pattern of overt conflict to intervene.

12. On such mock acts see Culpeper’s (1996) seminal study. 
attention to the fact that it's hot inside the car in a friendly and joking tone - in other words, she tries to align with the owner in order to resolve the situation. However, this is not what happens here, as the intervening person continues with a 'casual' remark "But, the police are coming right now", which is clearly menacing. Note, however, that even this menacing remark is made in an indirect way: the intervening person does not directly invoke New Jersey law about keeping pets in hot cars, and although she indicates that someone has called the police, implying that such action is against the law, she hides her agency by saying "the police are coming" (instead of "I've called the police”).

In sum, the intervention begins as a fake or mock alignment attempt, which transforms into a clear expression of disalignment from the wrongdoer.

Our data shows that mock alignment can occasionally take place in a jocular form (see Haugh 2010), as in example (3):
Abusive boyfriend
A couple is arguing in the park. Bystanders overhear the argument but seem conflicted over intervention. An elderly female bystander decides to intervene.
1. Boyfriend: Stop crying. Shut up!
2. Elderly female: Hey buddy! Cool it!
3. Boyfriend: Ma'am, can you just let us do our own thing? It's my girlfriend. Can you just leave us alone?
4. Elderly female: No. That's now how you treat someone. How about I call the cops?

Here the intervener, an elderly woman, addresses the abusive person by uttering "Hey buddy! Cool it!”. Calling the wrongdoer 'buddy' in an accentuated and ironic tone is clearly conflictive, as this idiomatic expression conveys the opposite of what it means literally: the person it is addressed to is not a friend by any means. Whilst 'buddy' is not necessarily used to belittle, it is pragmatically appropriate to signal disagreement or opposition, and this meaning is even stronger in this interaction due to the emotive context and also to the age gap between the wrongdoer and the intervening person.

In cases of 'overt conflict', the outspoken person may or may not directly align with the victim. In example (1), for instance, the outspoken person does not directly address the lesbian couple. In some other cases, however, disalignment from the wrongdoer comes together with overt alignment with the victim, as example (4) shows:

Abusive boyfriend

A couple is arguing in the park. Bystanders overhear the argument but seem conflicted over intervention. A young female, who is with a couple of friends, decides to intervene.

1. Boyfriend: Natalie sit down and listen to me. [pushes Natalie] प०D2. Young female: I could see you from up there. You do not push a woman out in public. That is complete bullshit.

DD०3. Young female: [turning to Natalie] Seriously, do you need a ride home?

4. Boyfriend: Natalie, sit down. This is my girlfriend. 
5. Young female: Wait. Who are you talking to? She is not a dog. You are just a little punk-ass kid and getting on my last nerve.

After clashing with the abusive person, the intervener turns to the victim, offering "a ride home". This affiliative attempt seems to boost the disalignment from the wrongdoer - which takes place in the form of the expletives 'bullshit' (to refer to the situation) and 'punk-ass kid' (a person reference term) in addressing the abuser - as claiming commonality with the victim conveys a clear message. ${ }^{13}$

In fact, alignment situated in intervention has a clear disaffiliative metamessage (Jaworski 1993), and an intervention can take a purely affiliative form, i.e. without an overt challenge taking place. We refer to such cases as 'covert conflict' (see Figure 1) because these acts - which are ritualistic performances that symbolise the wrongdoer's inappropriate behaviour - are also conflictive. Example (5), which is from the same episode as example (4), representing the abuse of a young woman Natalie by her 'boyfriend' - illustrates the operation of such covert clashes:

\section{Abusive boyfriend}

A couple is arguing in the park. Bystanders overhear the argument but seem conflicted over intervention. An elderly female bystander decides to step in.

1. Boyfriend: You are a whore that is useless. There is no point in being with you anymore. You are freaking useless. Go!

प्र०2. Elderly female: [wraps her arm around Natalie, looks disapprovingly at the boyfriend, and escorts her away from the abusive boyfriend.]

This time an elderly female intervenes as the same staged abusive conversation takes place between the couple as in example (4) above. She does not utter anything, but simply steps in and escorts Natalie away from the abusive boyfriend, while her facial expression signals disapproval. ${ }^{14}$ Whilst no overt challenge takes place here, this silence can be described as a meaningful one (Jaworski 1993), as it expresses disalignment from the wrongdoer. Also, the body language of the intervener (wrapping her arm around Natalie) is a common sign of protective alignment (see Kinsbourne 2006).

So far we have argued that the ritual of outspokenness can manifest itself as overt and covert conflict, and in different behavioural patterns. In addition to this, as our data indicates, there is also a significant contextual variation in the conversational argumentative patterns of these acts. In general, argumentation patterns of intervention include:

1. moral judgements of the wrongdoer's behaviour.

This is what the extracts that have been studied so far represent in the contexts of overt conflict (see examples 1-4) and covert conflict (example 5). Other argumentation patterns in the context of intervention are:

13. See Pan (2013) on pragmatics acts of commonality.

14. We intentionally use a non-verbal case here to describe covert disallignment: as example (5) illustrates, the act of disallignment can be as indirect as the elderly female's behaviour here, who manages to disalign from the wrongdoer without uttering a word. 
2. highly mitigated verbal utterances in the case of covert conflict, i.e. interventions in which, unlike in the cases studied above, the outspoken person attempts to tone down the negative impact of the intervention on the wrongdoer, and

3. divine appeals - in the case of overt conflict - i.e. cases when instead of directly criticising the wrongdoer the outspoken person appeals to the wrongdoer's morality by invoking God. ${ }^{15}$

It is pertinent to note about pattern no. 2 that intervention in general tends to be mitigated to some extent, as our data show, supposedly because this is an act of aggression that aims to reconstruct the normative order. However, when the context affords this, conflict can become so highly mitigated that it becomes covert, as the following examples illustrate:

Gay athlete comes out to his friends

Friends are at a busy shopping centre and a gay athlete tells his buddies that he is gay. His friends start to tease him and say homophobic slurs. A female overhears the teasing and steps in immediately and says the friends should not tease the gay person and they should not be so hard on him. Line 1 below takes place after the 'friends' of the gay athlete have already started to comprehend the situation, and the athlete makes the actual coming out.

1.Gay Athlete: I have something to tell you guys.

2. Friend: Stop playing bro! You are gay? G-A-Y? [starts laughing and backs away from gay athlete]

3. Gay Athlete: Yes.

4. Friend: You really don't like females? You don't like girls? You know what we call males that like men?

प0 50. Young female: Ya'll wrong. I heard the conversation. Ya'll ain't right. That's your friend?

6. $\quad$ Friend: That was my friend.

7. Young female: What do you mean was? That shouldn't stop you guys from being friends.

$[\ldots]$

In example (6), the young female who intervenes not only reminds the wrongdoer about the improperness of the act, but also attempts to mediate between the wrongdoer and the gay athlete. Whilst this intervention, as many other types of intervention, is conflictive, and the female first disaligns from the wrongdoer ("Ya'll wrong. [...] Ya'll ain't right"), as the interaction unfolds, in line 5 the woman mitigates the previous intervention. The utterance "What do you mean was? That shouldn't stop you guys from being friends" is open to be interpreted as an indirect 'offer' to transform disalignment into alignment both between 1) the intervener and the wrongdoers, and 2) the wrongdoers and the victim; addressing the wrongdoer as one of the "guys" expresses familiarity (see Heyd 2010). One can observe a similar interpersonal dynamics in example (7):

15. In 78 out of the 117 interactions the first pattern is followed, whilst highly mitigated utterances occur in 27 cases and divine appeals in 12 cases. 
Mother forces her daughter to tan

Mother and daughter argue over getting a tan. The mother insults daughter saying she looks too pasty and white, and the daughter says she does not want to get cancer.

1. Mother: You're gonna look so much better with a tan. You do not look healthy. You are gonna do it whether you want to or not. Get in the booth right now.

2. Daughter: I don’t want to. You know I don’t tan.

3. Mother: Yea. But look at you! [pause] You are pasty white. Listen honey we are here for a reason. Look at those girls. They look great.

$\square 4$. Young female: Thanks. But I still think she looks pretty. [...] I think she rocks it.

In this interaction the young female aligns with the victim in a clearly mitigated way hence decreasing the indirect disaffiliative message that this alignment attempt triggers - as she says thank you to the mother (which is both a mitigator and a discourse marker of disagreement). Note that the dynamics of the interaction facilitates this mediation attempt: the young female is directly referred to by the mother - in most cases in the data studied bystanders are not acknowledged until they intervene - and it seems as though, for the young female, this reference offers an indirect invitation to intervene.

As regards the third argumentative pattern, in some overt conflicts the outspoken person, instead of criticising the wrongdoer's behaviour, invokes God into their rationale for standing up, as the following example illustrates:

Gay parents verbally abused

This is the same setting as the one featured in example (1): a server harasses a lesbian couple.

1. Server: Are you guys a couple? And you are raising kids like that? Well, they need dads. I am not the one in public kissing all over a woman in front of my kids. That's not ... I actually have morals and standards.

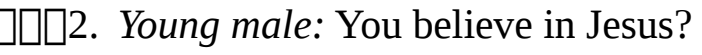

3. Server: Do I? What are you trying to tell me?

4. Young male: Don’t judge. That simple. I'll never judge you and I try not to judge other people.

Whilst this type of intervention is an overt form of behaviour (unlike e.g. example 6), due to its appealing characteristic it seems to be less conflictive (at least from an analytic point of view) than interventions which openly criticise the wrongdoer's behaviour (see the first category), in the form of statements such as "You are the worst...”, "I can’t believe you...”, and so on.

This list of argumentation patterns is not exclusive, i.e. it only reflects the ones we could observe in the WWYD data. The choice of a given pattern seems to be influenced not only by dyadic contextual factors, such as the physical and social power relationships involved, but also by the number and attitude of bystanders. As 
ritual intervention evokes normative social values as a performance, it operates as a direct or indirect appeal to a broader alleged or real audience. The word appeal should be emphasised here for the following reason. The competition to align with bystanders is present in any conflict talk; as Goffman (1967:25) puts it, "[i]n aggressive interchanges the winner not only succeeds in introducing information favourable to himself and unfavourable to others, but also demonstrates that as interactant he can handle himself better than his adversaries." However, what Goffman labels as 'demonstration' does not manifest itself in every conflict talk, as an appeal to support: for example, in certain conflict settings there is no audience to appeal to. The ritual of outspokenness is an example par excellence for cases when language aggression triggers appeal. The appellative nature of the rituals is illustrated by the fact that in some cases, when the intervening person is not alone, bystanders who are not familiar with the intervener and their group also join the conversation to support the outspoken person. Thus, the interaction between the outspoken person and the wrongdoer is not a dyadic one (see also Section 1): instead, it should be captured as a potential 'competition' between the outspoken person and the wrongdoer to become alignd with the bystanders/side participants-to-be. In order to show this point, let us revisit examples (1) and (2):

\section{(1) (reproduced)}

Lesbian parents verbally abused

1. Server: You're gay and you have kids? It's bad enough that you are lesbians but that they don't have a father. [pause] I think that is kind of bad. You don't feel uncomfortable - people watching you? Isn't it bad for the kids? I think it's terrible!

2. [Lesbian couple does not answer and looks very embarrassed.]

प्र०3. Young male: Sorry, but you are just being rude. It's completely inappropriate when someone comes into a restaurant to have breakfast with their family that you question their life choices.

4. $\quad$ Server: I just think I am entitled to my own opinion.

5. Young male: You are entitled to your opinion but this is not the place to voice your opinion.

पढ6. Server: Is it just me that's upset? [looks to different directions in the restaurant]

In line 6, after being challenged, the server makes a (counter-)appeal to the bystanders' morality, in order to validate her action. This is not a symbolic attempt, as shown by the data: as the server makes this appeal in several versions of the same scene, in one interaction a bystander, in response, gives an overt 'thumbs-up' to the server. Yet, the affiliative attempts of the outspoken person and the wrongdoer are not on a par, in that any intervention is an implicit invitation to bystanders to join as supporters, whilst the wrongdoer has to recruit supporters explicitly, as in (1). Accordingly, as the data show, rituals of outspokenness tend to attract bystanders to turn into side participants without any explicit invitation, as shown in excerpt (2), which is reproduced below:

(2) (reproduced)

Dog left inside a hot car 
1. Female: It' just so hot in there. [...] But, the police are coming right now.

2. Dog owner: You called the cops? How is any of that your concern?

3. Female: The dog is in there panting and could die. That's our concern. Not you.

4. Dog owner: It's just a dog.

5. Male: I have pets at home that I consider my family.

In general, rituals encourage participation due to their mimetic nature; as Collins (2004) demonstrates, rituals operate in "chains", i.e. a ritual action is open to trigger a number of similar actions. Yet, participation is particularly salient in the data studied, supposedly because clearly immoral acts like leaving a dog inside a hot car generate a clear common ground (e.g. empathy) between the outspoken person and other bystanders.

Figure 2 illustrates the interpersonal operation of the ritual of outspokenness (as well as silence and physical action, as in example 5):

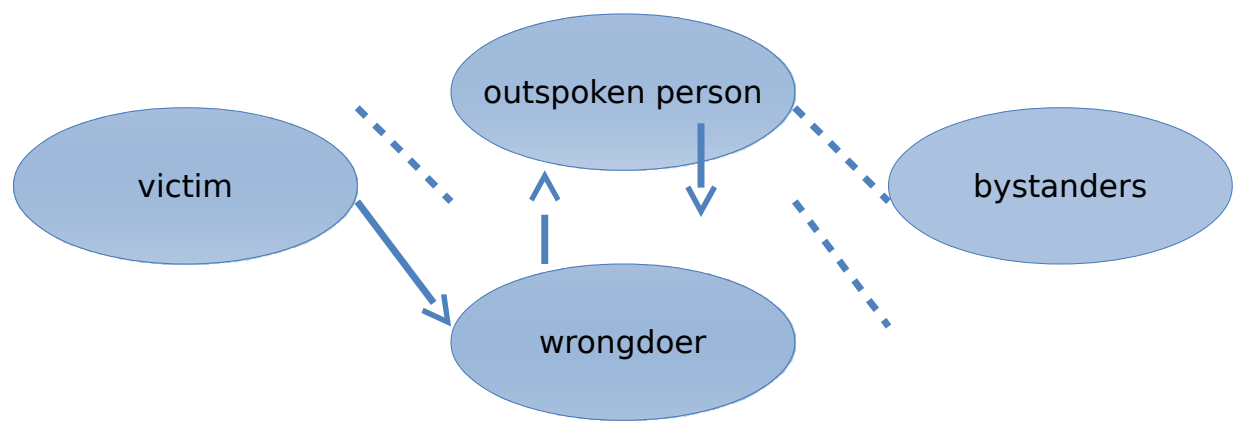

Figure 2: The interpersonal setting of conflicts of outspokenness

The arrows represent the direction of conflict: the outspoken person enters into a conflict with the wrongdoer, and the wrongdoer, in principle, enters into a conflict with the victim, although as the broken arrow pointing towards the outspoken person illustrates, they can counter-challenge the outspoken person as well. The dashed lines represent alignment attempts: the outspoken person not only aligns, either directly or indirectly, with the victim, but also with bystanders, by animating (claimed or real) social values; the same can be done by the wrongdoer's counter-appeal, except that this counter-appeal needs to be an overt one, as in example (1).

Note that the model proposed here is set into operation only if it is clear that the victim has been abused, and the bystanders are able to empathise/form a common ground with them. If, for example, an improper action of A against B takes place after a previous improper action committed by $\mathrm{B}$ against $\mathrm{A}$, it is less likely to trigger intervention, as example (9) illustrates:

\section{Clumsy teen server drops food on floor}

Scene no. 1:

A teen server drops food on the floor, puts it back on the plate and serves it to a customer. Many customers who see this happening intervene, telling the teen not to serve the dropped food. 
1. Teen: Here you go. [serving a plate of food after he dropped it on the floor]

C2. Customer 1: Hey didn't you just drop that? And you gonna serve that to them?

3. Teen: Our floor is clean.

4. Customer 2: You can't serve this to someone.

Scene no. 2:

This time a customer berates the teen server upon arrival to the restaurant. The server drops this customer's food on the floor but serves it anyway. Almost no customers step in to say the food has touched the floor.

1. Mean Customer: Hey Carrot Top! You are just a server. Who cares how we treat him.

[makes an order; the server takes it, then drops the food, puts it back on the plate and serves it to the customer]

2. Other customers: [silence]

Follow-up interviews:

Customer 2 non-intervener: Yes, I saw the server drop the food on the floor and serve it. Why should I start a commotion that's not relevant to my wellbeing.

Customer 3 non-intervener: Let him eat the dirty food. He is a dirty man.

In the first scene, customers intervene because the improper act clearly violates their moral order. However, the same act is evaluated differently in the second scene, due to the customer's previous abusive behaviour. It can be argued that in a sense that in this latter scene being silent operates in an equally disaffiliative way with being outspoken in other contexts: the bystanders obviously take the server's side, as is made clear by Customer 3's comment in the follow-up interview, and they express disalignment from the abusive person by failing to provide help for him.

\subsection{Failure to perform the ritual}

The motivations for intervening through rituals of outspokenness seem to be straightforward. In the follow-up interviews conducted by Quiñones, many side participants referred to some general moral reasons, such as "human decency", "fairness" and "civility", as motivators to intervene. Some other participants referred to empathy for the victim, evoked by their personal histories. For example, a female intervener who helped the couple in the scene featured in example (1) said that she intervened because she knows what it is like to be stigmatised for being different.

The motivations for failing to perform the ritual of outspokenness are more complex. First, whilst in many scenes depicted in WWYD it is relatively straightforward for many bystanders to take sides (see example 9), there are certain situations which are more ambiguous from a normative moral perspective. Once such an ambiguity occurs, bystanders are likely to find it difficult to intervene, even if they are able to form a common ground with the victim, as the following example illustrates:

$\underline{\text { Not the Father }}$ 
In a crowded restaurant a young pregnant woman is discussing with her friend whether or not to tell her boyfriend he is not the father of the child. The unsuspecting boyfriend arrives, and the woman lies, saying that she is pregnant with his child. After the father excuses himself from the table to call his parents and tell them the good news, some people sitting nearby intervene and non-aggressively advise the woman to come out with the truth. However, nobody actually intervenes when the boyfriend is there, by telling him that he is the victim of a lie.

1. Pregnant woman [to her friend]: I have thought about it and I have no other option. John is the better option for the father. I can't tell him that it's not his baby. It's really hard. I don't know what to do. [crying]

2. Customer 1: You know what? You seriously need to tell the truth to the guy.

3. Customer 2: After the baby is born you should have a DNA test.

4. Pregnant Woman: So, I shouldn't say anything to him?

5. Customer 2: No. Not yet.

6. $\quad$ Customer 1: Okay, I agree with that.

Follow-up interview

Customer 3: It's a personal matter.

The fact that 'appropriate' behaviour is co-constructed by Customer 1 and 2 indicates that this is a complex situation from a moral perspective, as there is no clear wrongdoer-victim relationship, which consequently only allows what MakriTsilipakou (1994) defines as "affiliative intervention". Also, as follow-up interviews make clear, bystanders such as Customer 3 found it morally problematic to make a fully-fledged intervention by informing the boyfriend that he is a victim of a lie, despite clearly empathising with him.

Secondly, unlike outspoken side participants who intervene, the (minority of) bystanders who fail to help the victim in scenes that clearly call for intervention refer to some lofty reasons for this failure. Interestingly, whilst there are two bystanders in our data who clearly admit unwillingness or inability to intervene (e.g. "I personally thought it was none of my business"), the other non-interveners give morally loaded explanations for not helping the victim. Example (11) illustrates this phenomenon:

$\underline{\text { Sikh refused job at restaurant }}$

Manager tells a Sikh man that he cannot wear his turban while at work, as he looks threatening. Whilst a number of customers help the Sikh, there are some others who do not; their responses are shown in the follow-up interview section.

1. Manager: Obviously you can't wear the head garb.

2. Sikh: What do you mean I can't wear the head garb?

3. Manager: I can't have you wear that. It's just part of our policy here that everyone is non-denominational.

4. Sikh: You want me to take off the turban?

[...] 
5. Manager: Look. I am going to be honest with you. I can't hire you looking the way you look.

6. Sikh: Looking the way I look?

7. Manager: It's threatening.

Follow-up interviews

Customer 1 non-intervener: The bottom line is if there is a dress code and you want the job - jobs are hard to get - you follow the dress code. That's how I feel. If I really wanted the job I'd take the turban off.

Customer 2 non-intervener: I think in America you should dress and behave as an American. Fit in with the society. I know it's not politically correct in the United States and everybody wants to be more open. I am open myself, but I'm open also to change my behaviour.

Customer 3 non-intervener: That guy was out of line. He was clearly discriminating against the guy. No. How can you do it? I'm embarrassed that I did not jump up.

Though Customer 3 simply admits that he feels embarrassed for failing to help, Customer 1 and Customer 2 provide moral grounds for their behaviour. The researcher has no means to peep into the interactants' minds, and sometimes people simply can be proud of not helping a victim (e.g. when someone dislikes the victim). However, the recurrence of moral argumentation in the accounts of those who failed to live up to socially normative expectations - and who are made aware of this failure, and the fact that they are being watched, as Quiñones confronts them in the follow-up interview - suggests that usually these narratives aim to reconstruct bystander identities (see Freeman 2001). By reconstruction we mean that, as identity is (co-)constructed in interaction, in such accounts the narrators - who seem to be aware of the fact that they were doing something improper - attempt to form a positive image of themselves towards others. What further indicates the reconstructive nature of these accounts is that practically all of those who did not step in to help the victim and did not admit defeat as Customer 3 above, unlike the interveners refused to show their face on camera, even if they agreed to comment on their behaviour. Their attempt to interactionally reconstruct their identities points to the argument made in Section 1: settings of abuse impose a moral obligation on bystanders to intervene.

In relation to the moral obligation, it is pertinent here to refer to an experiment, which Kádár (2013: 171-3) previously conducted, by interviewing 14 people who observed and experienced abusive practices within certain groups and failed to help the victim, and who were later made aware of their failure; in addition, Kádár in the same experiment examined 21 anecdotal cases retold by people who failed to intervene in an abuse incident. Whilst the abuse in such cases differed from the one studied in this paper, the moral implication is fairly similar to that in the WWYD data. As the experiment made clear, those who failed to stand up for others tended to describe these events by using euphemistic labels, and in general they downgraded the impact of the happenings on the victim. As Kádár (2013: 172-3) argues:

Such evaluations [...] seem to be motivated by the awareness and anticipation that [...] being a passive onlooker is problematic if an event is morally objected to by the public. That is, people in retrospect may re-evaluate their historically situated understanding of the given act. 


\section{Discussion: Findings and future research}

The present paper has filled an important knowledge gap in the field, by examining an understudied form of ritual behaviour, hence contributing to pragmatics and research on interpersonal rituals. We have argued that rituals of outspokenness manifest themselves in various forms of (dis)affiliative behaviour as overt and covert conflicts, and through a number of conversational argumentative patterns. Along with modelling the interpersonal operation of this phenomenon, we have argued that there is a moral obligation triggered by settings of abuse (although such obligations are, of course, highly context dependent). This obligation is noteworthy from the perspective of the ritual researcher, as it indicates that there are certain situations that generate a straightforward ritual response. In such settings ritual reaction is an expected action, whilst non-acting by itself is also interpreted as an improper 'passive action'. The moral obligation, and the evaluations it triggers, are also relevant to research on (im)politeness and aggression, as Section 1 argued: the rightful aggression of interveners tends to be evaluated positively, and the passive and often non-aggressive behaviour is usually perceived negatively. This points to a major gap between ritualised aggression (see Bax 2002), which (re-)enacts normative social values, and more ad hoc forms of aggression, which tend to be perceived as impolite, rude, and so on. As ritualised aggression restores (or represents) the normative beliefs of the performer(s) - and that of most of the observer(s) - it is aggressive in the sense that it triggers conflict in more or less indirect ways. ${ }^{16}$ However, due to its normative nature a ritual of outspokenness is not necessarily perceived as destructive or even aggressive by the performer and the bystanders/side participants, i.e. unlike many other forms of language aggression it is not "directed towards the goal of harming and injuring another living being who is motivated to avoid such treatment” (Baron and Richardson 1994, cited in Culpeper 2011: 20).

It is pertinent to note that the present research represents a stage in a cross-cultural research project conducted by Kádár (2015, forthcoming), which aims to compare ritual practices across cultures. Rituals of outspokenness as described by the present paper seem to be culture-specific. We have examined these rituals by using North American data, and previous research suggests that there is considerable cultural variation when it comes to standing up for a victim (e.g. Menesini et al. 1998; Kanetsuna et al. 1996). ${ }^{17}$ In certain cultures, such as the Japanese, this act seems to be less expected to take place than in other cultures, although expectations in this respect seem to be a matter of degree, rather than clear-cut cross-cultural differences. For example, as Donahue (1998: 18) argues, it is relatively irregular in Japan, compared to Western cultures (and North America, in particular), to stand up for victims of abuse, in particular if the victim is not closely related to someone. Thus, 'morality' as featured in this paper represents a supposedly Judeo-Christian understanding of moral attitude, ${ }^{18}$ and this entails that rituals of outspokenness are more prevalent in cultures in which "Good Samaritan" behaviour is regarded as normative than in others (see Tang et al. 2008).

16. A different degree of indirectness, by itself, does not distinguish ritualised aggression from other types of aggression, which can also be more and less indirect.

17. As Archer's (1999) insightful study indicates, there is also some sub-cultural variation in this respect, i.e. even in cultures in which being outspoken is valued there are contexts (such as in the military), which discourage such ritual practices.

18. See Haugh and Kádár (2014, forthcoming) on the culture specificity of morality in terms of pragmatic behaviour. 
It is a task for future research to clarify cross-cultural overlaps and differences between forms of ritualised aggression that restore the normative order, by looking into culturally-specific moral expectations. The model offered in this paper, which approaches ritual practices from the perspective of their relational operation, can provide a starting point for such inquiries.

\section{References}

Alexander, Jeffrey C. 2004. Cultural pragmatics: Social performance between ritual and strategy. Sociological Theory 22(4): 527-73.

Archer, David 1999. Exploring "bullying” culture in the para-military organisation. International Journal of Manpower 20(1/2): 94-105.

Bax, Marcel 2002. Rites of rivalry: Ritual interaction and the emergence of indirect language use. Journal of Historical Pragmatics 3(1): 61-105.

Bell, Catherine. 1997. Ritual: Perspectives and Dimensions. Oxford: Oxford University Press.

Boltanski, Luc, and Laurent Thévenot 2000. The reality of moral expectations: A sociology of situated judgement. Philosophical Explorations: An International Journal for the Philosophy of Mind and Action 3(3): 208-31.

Burdelski, Matthew 2013. "I'm sorry, flower": Socializing apology, relationships and empathy in Japan. Pragmatics and Society 4(1): 54-81.

Collins, Randall. 2004. Interaction Ritual Chains. Princeton, NJ: Princeton University Press.

Culpeper, Jonathan 1996. Towards an anatomy of impoliteness. Journal of Pragmatics 25(3): 349-67.

Culpeper, Jonathan 2011. Impoliteness: Using Language to Cause Offence. Cambridge: Cambridge University Press.

Dijker, Eric D., James H. Wirth, John B. Pryor, Glenn D. Reeder, and Kipling D. Williams 2013. When do we ostracize? Social Psychological \& Personality Science 4(1): 108-15.

Drummond, Kent 1989. A backward glance at interruptions. Western Journal of Speech Communication 53(2): 150-166.

Freeman, Mark 2001. From substance to story: Narrative, identity, and the reconstruction of self. In: Jens Brockmeier, and Donal A. Carbaugh (eds.) Narrative and Identity. Amsterdam: John Benjamins, 283-298.

Garcés-Conejos Blitvich, Pilar 2009. Impoliteness and identity in the American news media: The "Culture Wars". Journal of Politeness Research 5: 273-303.

Garcés-Conejos Blitvich, Pilar 2010. A genre approach to the study of im-politenes. International Review of Pragmatics 2(1): 46-94.

Goffman, Erving 1967. Interaction Ritual: Essays on Face-to-Face Behavior. New York: Anchor Books.

Goffman, Erving 1979. Footing. Semiotica 25(1/2): 1-30.

Gorsuch, Richard L., and John Ortberg 1983. Moral obligation and attitudes: Their relation to behavioural intentions. Journal of Personality and Social Psychology 44(5): 1025-28.

Graham, Sage Lambert 2007. Disagreeing to agree: (Im)politeness and identity in a computer-mediated community. Journal of Pragmatics 39(4): 742-59.

Haugh, Michael 2010. Jocular mockery, (dis)alignment, and face. Journal of Pragmatics 42(8): 2106-19. 
Haugh, Michael, and Dániel Z. Kádár 2014. Politeness in China and Japan. Amsterdam and Philadelphia: John Benjamins.

Hayashi, Takuo 1996. Politeness in conflict management: A conversation analysis of dispreferred message from a cognitive perspective. Journal of Pragmatics 25: 227-55.

Heritage, John, and Anna Lindström 2012. Knowledge, empathy and emotion in a medical encounter. In: Anssi Peräkylä, and Marja-Leena Sorjonen (eds.) Emotion and Affect in Interaction. Oxford: Oxford University Press: 256-73.

Heyd, Theresa 2010. How you guys doin'? Staged orality and emerging plural address in the television series Friends. American Speech 85(1): 33-66.

Holmes, Janet, and Meredith Marra 2004. Leadership and managing conflict in meetings. Pragmatics 14(4): 439-62.

Ide, Risako 1998. 'Sorry for your kindness': Japanese interactional ritual in public discourse. Journal of Pragmatics 29(5): 509-29.

Jaworski, Adam 1993. The Power of Silence: Social and Pragmatic Perspectives. London: Sage.

Kádár, Dániel Z. 2013. Relational Rituals and Communication: Ritual Interaction in Groups. Basingstoke: Palgrave Macmillan.

Kádár, Dániel Z. 2014 (in press). Heckling: A mimetic-interpersonal perspective. Journal of Language Aggression and Conflict 2(1).

Kádár, Dániel Z., and Michael Haugh 2013. Understanding Politeness. Cambridge: Cambridge University Press.

Kinsbourne, Marcel 2006. Gestures and embodied cognition: A neurodevelopmental interpretation. Gesture 6(2): 205-14.

Lorenzo-Dus, Nuria, and Garcés-Conejos Blitvich, Pilar (Eds.) 2013. Real Talk: Reality Television and Discourse Analysis in Action. Basingstoke: Palgrave Macmillan.

Lüger, Heinz-Helmut 1983. Some aspects of ritual communication. Journal of Pragmatics 7(6): 695-711.

Makri-Tsilipakou, Marianthi 2004. Interruption revisited: Affiliative vs. disaffilitative intervention. Journal of Pragmatics 21(4): 401-26.

Manning, Rachel, Mark Levine, and Alan Collins 2007. The Kitty Genovese murder and the social psychology of helping: The parable of the 38 witnesses. American Psychologist 62(6): 555-62.

Marques, J. M. 1990. The black-sheep effect: Out-group homogeneity in social comparison settings. In: D. Abrahams, and M. A. Hogg (eds.) Social Identity Theory: Constructive and Critical Advances. New York: Springer, 131-51.

Marques, J. M., and Paez D. 1994. The "black-sheep effect": Social categorization, rejection of in-group deviates and perception of group variability. European Review of Social Psychology 5: 37-68.

Mey, Jacob 2008. "Impeach or exorcise?” Or, what is in the (common) ground? In: István Kecskés and Jacob Mey (eds.) Intention, Common Ground and the Egocentric Speaker-Hearer. Berlin and New York: Mouton de Gruyter, 255276.

Pan, Yuling 2013. Interactional sociolinguistics as a research perspective. The Encyclopedia of Applied Linguistics. London: Blackwell. DOI: 10.1002/9781405198431.wbeal0552

Rampton, Ben 2009. Interaction ritual and not just artful performance in crossing and stylization. Language in Society 38(2): 149-76. 
Sommer, Kristin, and Juran Yoon 2013. When silence is golden: Ostracism as a resource conservation during aversive interactions. Journal of Social and Personal Relationships 30(7): 901-19.

Stivers, Tanya, Loranza Mondada, and Jakob Steensig (eds.) 2011. The Morality of Knowledge in Conversation. Cambridge: Cambridge University Press.

Takahashi, Tomoko, and Leslie Beebe 1987. Development of pragmatic competence by Japanese learners of English. The JALT Journal 8(2): 131-56.

Van Dijk, Teun A. 1997. The study of discourse. In: Teun A. Van Dijk (ed.) Discourse as Structure and Process. London: Sage, 1-34.

Whutnow, Robert 1989. Meaning and Moral Order: Explorations in Cultural Analysis. Berkeley, CA: University of California Press.

Williams, K. D., and K. L. Sommer 1997. Social ostracism by one’s coworkers: Does rejection lead to loafing or compensation? Personality and Social Psychology Bulletin 23: 693-706.

Williams, K. D, and L. Zadro 2001. Ostracism: On being ignored, excluded, and rejected. In M. R. Leary (ed.) Interpersonal Rejection. Oxford: Oxford University Press, 21-53.

Wynn, Rolf, and Michael Wynn 2006. Empathy as an interactionally achieved phenomenon is psychotherapy: Characteristics of some conversational resources. Journal of Pragmatics 38(9): 1385-97. 